Louisiana State University

LSU Digital Commons

Faculty Publications

Department of Biological Sciences

$11-1-2003$

\title{
An analysis of single clutch paternity in the burrower bug Sehirus cinctus using microsatellites
}

Jeremy M. Brown

Indiana University Bloomington

Aneil F. Agrawal

Indiana University Bloomington

Edmund D. Brodie

Indiana University Bloomington

Follow this and additional works at: https://digitalcommons.Isu.edu/biosci_pubs

\section{Recommended Citation}

Brown, J., Agrawal, A., \& Brodie, E. (2003). An analysis of single clutch paternity in the burrower bug Sehirus cinctus using microsatellites. Journal of Insect Behavior, 16 (6), 731-745. https://doi.org/ 10.1023/B:JOIR.0000018317.55712.d3

This Article is brought to you for free and open access by the Department of Biological Sciences at LSU Digital Commons. It has been accepted for inclusion in Faculty Publications by an authorized administrator of LSU Digital Commons. For more information, please contact ir@lsu.edu. 


\title{
An Analysis of Single Clutch Paternity in the Burrower Bug Sehirus cinctus Using Microsatellites
}

\author{
Jeremy M. Brown, ${ }^{1,2}$ Aneil F. Agrawal, ${ }^{1}$ and Edmund D. Brodie III ${ }^{1}$ \\ Accepted July 16, 2003; revised August 13, 2003
}

Recent studies of the burrower bug, Sehirus cinctus, have examined the genetic basis of parental care. An understanding of the burrower bug mating system, and the subsequent pattern of offspring relatedness that this system generates, is critical to further interpret genetic data. To this end, we developed three consistently amplifiable highly polymorphic microsatellite loci and used them to determine genotypic patterns at the level of both the population and the single clutch. We found that all clutches were sired by single males. Further, we find no evidence for inbreeding. We hypothesize that single paternity within a clutch may play an important role in reducing the potential for sibling rivalry, by increasing the relatedness among clutchmates.

KEY WORDS: microsatellites; Cydnidae; Hemiptera; mating system; paternity; inbreeding.

\section{INTRODUCTION}

Investigations of mating system are important because mating system affects (or is affected by) so many other aspects of the natural history of an organism, including the distribution of genetic components of variance (Wade, 1996), the potential for sexual conflict over parental care levels (Mock and Parker, 1997), sibling rivalry over parental efforts (Houston and McNamara, 2002; Sheldon, 2002) and sexual selection (Andersson, 1994). Genetic

${ }^{1}$ Department of Biology and Center for the Integrative Study of Animal Behavior, Indiana University, 1001 East 3rd Street, Bloomington, Indiana 47405.

${ }^{2}$ To whom correspondence should be addressed at Section of Integrative Biology PAT 141, 1 University Station C0930, Austin, Texas 78712-0182. e-mail: jembrown@mail.utexas.edu. 
mating patterns (as opposed to behavioral patterns) can be directly observed through the parental contributions to individual offspring as measured by molecular markers. Surprising insights have been gained into systems that are well studied and thought to be well understood, through the use of such techniques. One striking example is the number of extrapair copulations among bird species previously thought to be monogamous (Birkhead and Møller, 1992). Genetic studies of mating patterns can also help us to understand other aspects of a species' biology. For example, paternity analysis in the water bug Abedus herberti shows that males are highly likely to be the sire of the eggs they tend (Smith, 1979).

Two parameters are of particular interest when investigating patterns of relatedness among offspring: (i) levels of polygamy and (ii) relatedness between mates. Among insects, genetic investigations of mating systems have uncovered a wide variety of patterns of paternity, ranging from monogamy to extreme polygamy (Nalepa and Jones, 1991; Moritz et al., 1995) even within the same genus (Estoup et al., 1995). Females in the majority of insect species appear to mate multiply (Arnqvist and Nilsson, 2000). However, the forces and constraints generating such patterns are often not well understood (Nalepa and Jones, 1991). Mating system, therefore, must be determined on a case-by-case basis for systems of interest. Matings between closely related individuals (inbreeding) may also affect the degree of relatedness between offspring, as well as offspring fitness (Mutikainen and Delph, 1998; Koelewijn, 1998; Hamilton, 1964). A knowledge of such structure, if it exists, is important to understanding how it may have affected (or been affected by) the evolution of other behaviors, such as maternal care (Margulis, 1997).

The burrower bug, Sehirus cinctus (Hemiptera; Cydnidae), has become a system of interest in behavioral genetics due to the existence of maternal care behaviors under complex genetic control (Kight, 1995; Kight and Cseke, 1998; Agrawal et al., 2001). Little is currently known about mating system in this species, even though mating can impact the evolution of maternal care. Mating most likely occurs in the summer and upon emergence in the spring. Limited interactions between males and females have been observed in the laboratory as soon as adulthood is reached, with multiple males pursuing a single female (unpublished data). Mating is much more frequent just after adults have passed through an artificial "winter" of 3 to 5 months in the lab, during which temperature and photoperiod are adjusted to simulate a change in seasons. Mating occurs through a posterior-to-posterior arrangement (Fig. 1), allowing contact between the male aedeagus (located in the ninth abdominal segment) and the female plate-like genitalia (located on the ventral surface of the eight and ninth abdominal segments) (Dupuis, 1970). Males will successfully mate multiple females (unpublished data). 


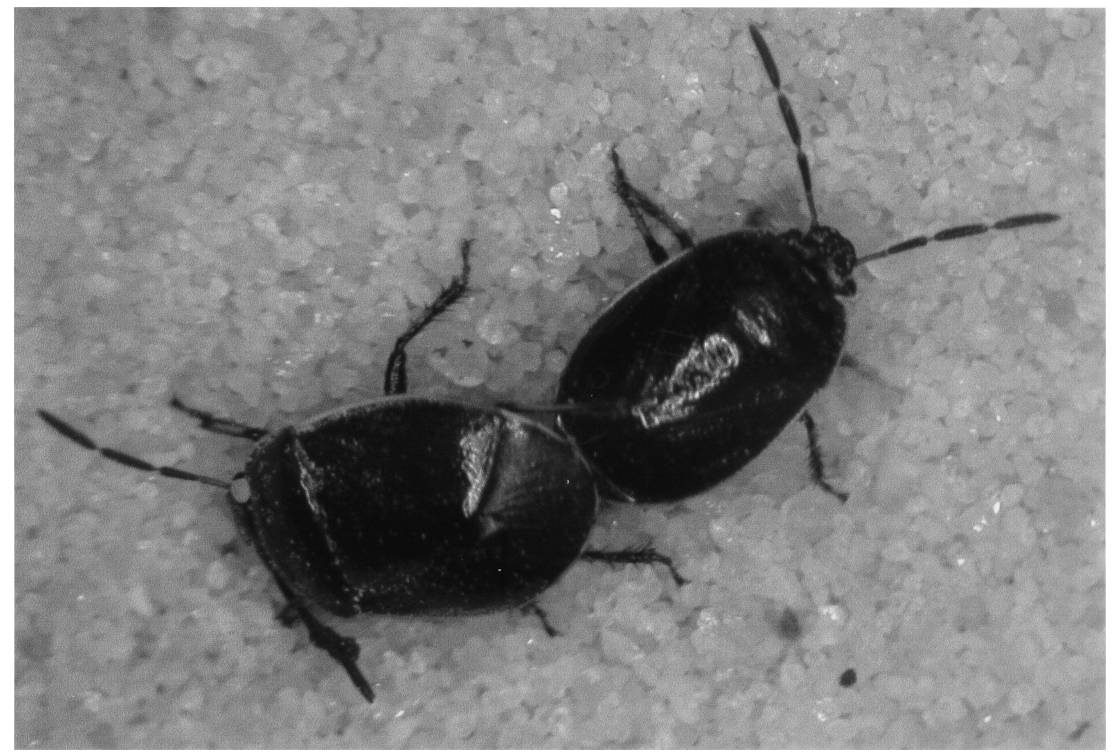

Fig. 1. Copulation between a burrower bug (Sehirus cinctus) female (left) and male (right). Photo: Patrick Alexander.

Copulation time has not been rigorously examined, but copulations lasting at least $30 \mathrm{~min}$ have been observed in the laboratory (personal observation).

Burrower bugs overwinter as adults. Females emerge from overwintering and lay clutches of approximately 40-150 eggs during late spring (April and May) in the midwestern United States. Burrower bug mothers guard egg clutches until hatching ( $\sim 10$ days) and then provision offspring with small mint nutlets (Lamium spp.) through the first two nymphal instars ( $\sim 10$ days [Sites and McPherson, 1982; Agrawal et al., 2001]). Provisioning is directed to the clutch as a whole and unprovisioned clutches do not survive (Agrawal et al., 2001). Presumably, there is some level of offspring competition for provisioned resources. In the field, large numbers of individuals $(>100)$ can be found within a small area $\left(<1 \mathrm{~m}^{2}\right)$ containing dense stands of host plants (personal observation).

Mating system is of particular interest in burrower bugs, because it may influence the dynamics of maternal-offspring interactions and sibling competition. According to Hamilton's (1964) rule, higher levels of cooperation are expected to evolve among more closely related individuals, all else being equal. If multiple fathers (compared to a single father) make a genetic contribution to a clutch, the average relatedness among offspring will be reduced because groups of offspring will be related as half-sibs. Such reduced 
relatedness would also reduce the potential for cooperation or increase the potential for competition among offspring within a clutch.

Our primary aim was to determine the number of males siring each clutch, to understand the genetic context in which maternal-offspring and sib-sib interactions occur. Our secondary goal was to look for evidence of inbreeding, which could also influence within-clutch relatedness. This aspect of mating system is important for (i) understanding how different components of genetic variance contribute to evolution as well as (ii) providing insights into mate choice. We developed novel microsatellites and used them to genotype mothers and groups of their offspring. Mating system patterns were then inferred from these genotypes. To our knowledge this is the first study of mating system within the family Cydnidae.

\section{MATERIALS AND METHODS}

\section{Development of Microsatellites and Molecular Methods}

Sehirus cinctus genomic DNA enriched for tandem repeats (putative microsatellite loci) was obtained from Genetic Identification Services (GIS). Approximately 20 inserts containing tandem repeats were sequenced. Using Primer 3 software (Rozen and Skaletsky, 1998), PCR primers (Table I) were designed from sequences flanking repeats. Oligonucleotides were synthesized by Invitrogen, Inc. Genomic DNA extractions were performed using a Puregene ${ }_{\circledast}$ isolation kit (Gentra, Inc).

The following variations on the standard protocol for isolating DNA from 5-10 $\mathrm{mg}$ of fresh or frozen tissue were used. (i) Cell lysis was performed either by flash-freezing the individual with liquid nitrogen and grinding with a microfuge pestle prior to addition of cell lysis buffer or by manually shaking a 1.5-ml Eppendorf tube containing cell lysis buffer, one individual, and a 3-mm tungsten-carbide bead (Qiagen, Inc.). (ii) Treatment with RNase A was not used. (iii) DNA pellets were allowed to dry overnight after a $70 \%$

Table I. Primer Sequences Flanking Variable Microsatellite Loci in Sehirus cinctus

\begin{tabular}{lll}
\hline Locus & \multicolumn{1}{c}{ Forward primer $\left(5^{\prime}-3^{\prime}\right)$} & \multicolumn{1}{c}{ Reverse primer $\left(5^{\prime}-3^{\prime}\right)$} \\
\hline A3 & TCTGTCCGATGAACTTTTCATTT & GTTGGGGAGCCTTTTCCAT \\
A6 & TACGGGGATGAGATGTAGCC & CAGGTGCCATCCCTGTAAAT \\
A7 & GCGAAGGATATTCGAACTGC & ACGGGTGATTGACGACTGAT \\
A11 & GAGGGAGTGGTTGCGTCTAC & TGCGTGCTCGTAATGTTCTC \\
B8 & TTCACAATTCCGGATCATTT & CATCAGCACTTGATTGGATGA \\
\hline
\end{tabular}


ethanol wash. DNA was quantified using a TKO 100 fluorometer (Hoefer Scientific Instruments) and diluted in $\mathrm{ddH}_{2} \mathrm{O}$ to a final concentration of $\sim 100 \mathrm{ng} / \mu \mathrm{l}$, if possible. One of the two following thermal profiles was used: (a) $8 \mathrm{~min}$ at $95^{\circ} \mathrm{C}$, followed by 50 cycles of $1 \mathrm{~min}$ at $95^{\circ} \mathrm{C}, 1 \mathrm{~min}$ at $55^{\circ} \mathrm{C}$, and $1 \mathrm{~min}$ at $72^{\circ} \mathrm{C}$, with a final extension step of $5 \mathrm{~min}$ at $72^{\circ} \mathrm{C}$, or (b) 8 min at $95^{\circ} \mathrm{C}$, followed by 40 cycles of $1 \mathrm{~min}$ at $95^{\circ} \mathrm{C}, 1 \mathrm{~min}$ at $55^{\circ} \mathrm{C}$, and 1 $\min 45 \mathrm{~s}$ at $72^{\circ} \mathrm{C}$, with a final extension step of $10 \mathrm{~min}$ at $72^{\circ} \mathrm{C}$. The second profile was used to reduce the effects of short allele dominance and recheck the genotypes of putative homozygotes. The total reaction volume was $25 \mu \mathrm{l}$ and included 15-25 ng DNA, 0.5 U Taq polymerase (Promega), $1.5 \mathrm{~m} M \mathrm{MgCl}_{2}$ (3.5 mM MgCl 2 for multiplexed reactions), $1 \times$ PCR Buffer (Promega), $0.2 \mathrm{~m} M$ dNTP's (0.28 $\mathrm{m} M$ dNTP's for multiplexed reactions; NEB), and a $0.25 \mu M$ concentration of each primer. If large volumes of EDTA-containing DNA extract were used, the $\mathrm{MgCl}_{2}$ concentration was increased. For paternity analysis, three microsatellite loci (A6, A7, and A11) were amplified simultaneously in a multiplexed reaction. If results were ambiguous or nonexistent, the reaction was repeated with only one primer pair. Forward primers were either Hex- or Fam-labeled, with PCR products being run against an R500 Gensize standard (Genpak), and visualized using Genescan on an ABI 3700 Sequencer (Applied Biosystems). Genotyping was performed using Genotyper v3.7 (Applied Biosystems).

\section{Population Characterization}

Population allele frequency calculations were performed using the genotypes at five microsatellite loci from random samples of adult burrowers collected from a single field in Monroe County, IN. Genepop v $3.3 \mathrm{c}$ (Raymond and Rousset, 1995; http://wbiomed.curtin.edu.au/genepop/) was used to test for deviations from Hardy-Weinberg expectations (both globally and by locus, using a Markov chain method to estimate the exact $P$ value of the test [Guo and Thompson, 1992]), as well as to estimate values of $F_{\mathrm{IS}}$ (Weir and Cockerham, 1984). $F_{\mathrm{IS}}$ measures the reduction in heterozygosity of individuals due to nonrandom mating or inbreeding (Hartl and Clark, 1997). An $F_{\mathrm{IS}}$ of 0 would indicate no reduction in heterozygosity and implies random mating, whereas an $F_{\text {IS }}$ of 1 would indicate a total reduction in heterozygosity resulting from the continuous inbreeding of close relatives. A population-level sample containing individuals of different inbreeding histories should exhibit an association among loci for homozygosity not anticipated by genotype frequencies at single loci (Haldane, 1949; Bennet and Binet, 1956; Castric et al., 2002). A population with a mixed breeding history (some inbreeding and some random mating) should have 
an increased variance in the number of homozygous loci as compared to a randomly mating population, because a large number of homozygous loci will be found in inbred individuals instead of being randomly distributed throughout the population (Brown et al., 1980). To test for this pattern, we generated an empirically based null distribution of multilocus associations based on the number of homozygotes observed at each locus for all adults from the Monroe County, IN, population for which all five genotypes were known. Single-locus genotypes were randomly associated within individuals in a permutation test to generate 1000 simulated populations and the variance in number of homozygous loci per individual was calculated within each simulated population. The observed variance in number of homozygous loci was compared to this null distribution.

\section{Progeny Array Data}

Paternity analysis samples were obtained by collecting 26 previously mated female burrowers from the same population just prior to egg deposition and housing them in petri dishes containing a sand substrate, cover for nesting, and food and water ad libitum (Agrawal et al., 2001). By timing field collection just prior to egg deposition, females were able to be readily collected off of host plants and the egg clutches they later laid in the laboratory could be assigned to the correct mother with complete certainty. Additionally, it is unlikely that mating opportunities for females were drastically reduced, as males are rarely found at this time. Mothers were allowed to lay eggs and remain with offspring through hatching and rearing to the third instar. Upon reaching third instar, all offspring and their mothers were frozen at $-20^{\circ} \mathrm{C}$ for genotyping. All mothers and haphazardly chosen offspring (5-19 individuals) from each clutch were genotyped for three microsatellite loci (A6, A7, and A11). The paternity exclusion probability (given a known maternal genotype) was calculated using Gerud 1.0 (Jones, 2001) according to Dodds et al. (1996). Null alleles most likely exist at loci $\mathrm{A} 3$ and B8 (see discussion), so these loci were not used for paternity analysis.

Maternal and offspring genotypes were analyzed using Likelihood Analysis of Multiple Paternity (LAMP; Kichler et al., 1999). LAMP uses a maximum likelihood method to determine population-wide values for the proportion of clutches multiply sired $(m)$, reproductive skew (the proportion of a clutch sired by a single male) within a multiply mated clutch $(k)$, and mutation rate $(\mu)$ for a maximum of two fathers per clutch. For example, a parameter combination of $m=0.3$ and $k=0.6$ would mean that $70 \%$ $(1-m)$ of clutches are each sired by a single father, whereas $30 \%(m)$ of clutches are sired by two fathers each, where the dominant father sires $60 \%$ $(k)$ of the offspring. Likelihood values were found across all possible values 
of both reproductive skew $(k)$ and the fraction of clutches multiply mated $(m)$. Inferred paternal genotypes were also compared between clutches to test for polygyny by any males sampled through this progeny array.

Relatedness among offspring from a given clutch was calculated using Relatedness 5.0 (Queller and Goodnight, 1989). This program calculates the average genetic relatedness among and across groups (clutches). A 95\% confidence interval was obtained by jackknifing across clutches.

To test for inbreeding from the progeny array data, paternal genotypes were inferred from offspring genotypes by subtracting maternally contributed alleles. For those loci with paternal genotypes able to be unequivocally determined (assuming one father per clutch; see Results), pairwise relatedness values were calculated within mating dyads using the general estimator given by Lynch and Ritland (1999):

$$
\hat{r}_{x y}=\frac{p_{a}\left(S_{b c}+S_{b d}\right)+p_{b}\left(S_{a c}+S_{a d}\right)-4 p_{a} p_{b}}{\left(1+S_{a b}\right)\left(p_{a}+p_{b}\right)-4 p_{a} p_{b}}
$$

where $x$ is the reference individual (with alleles $a$ and $b$ ) and $y$ is the second individual (with alleles $c$ and $d$ ). The frequencies of alleles $a$ and $b$ are given as $p_{a}$ and $p_{b}$. Indicator variables $(S)$ can take values of 0 or 1 and are used to indicate sharing between a pair of alleles (e.g., if alleles $a$ and $c$ are identical, $S_{a c}=1$, and if they are different, $S_{a c}=0$ ). All estimates of relatedness for a pair of individuals were calculated twice (so that each member of a pair was used as the reference individual once and the second individual once) and the arithmetic average of the two estimates for each locus was found. Multilocus estimates of relatedness were calculated by weighting each locus according to the inverse of the sampling variance of estimates of relatedness coefficients (Lynch and Ritland, 1999), where the weight of each locus is given by

$$
w_{r, x}(l)=\frac{1}{\operatorname{Var}\left[\hat{r}_{x y}(l)\right]}=\frac{\left(1+S_{a b}\right)\left(p_{a}+p_{b}\right)-4 p_{a} p_{b}}{2 p_{a} p_{b}}
$$

where $w_{r, x}$ is the weight of the $l$ th locus in the estimation of $r_{x y}$. The multilocus estimate of relatedness is then

$$
\hat{r}_{x y}=\frac{1}{W_{r, x}} \sum_{l=1}^{L} w_{r, x}(l) \hat{r}_{x y}(l)
$$

setting $W_{r, x}$ equal to the sum of the weights over all loci. 
Table II. Heterozygosities (Observed and Expected), General Repeat Motif, Number and Size Range of Alleles, and Annealing Temperature for Variable Microsatellite Loci in Sehirus cinctus

\begin{tabular}{lccccccccc}
\hline Locus & $H_{o}{ }^{a}$ & $H_{e}{ }^{b}$ & \multicolumn{1}{c}{$F_{\mathrm{IS}}{ }^{c}$} & $\mathrm{H}-\mathrm{W}^{d}$ & $\begin{array}{c}\text { General repeat } \\
\text { motif }\end{array}$ & $n^{e} \begin{array}{c}\text { No. of } \\
\text { alleles }\end{array}$ & $\begin{array}{c}\text { Size range } \\
(\mathrm{bp})^{f}\end{array}$ & $T_{a}\left({ }^{\circ} \mathrm{C}\right)$ \\
\hline $\mathrm{A} 6$ & 0.95 & 0.91 & -0.058 & $0.844 \pm 0.001$ & $(\mathrm{CA})_{\mathrm{n}}$ & 76 & 16 & $133-179$ & 55 \\
$\mathrm{~A} 7$ & 0.90 & 0.90 & 0.008 & $0.425 \pm 0.002$ & $(\mathrm{CA})_{\mathrm{n}}$ & 77 & 27 & $220-413$ & 55 \\
$\mathrm{~A} 11$ & 0.77 & 0.83 & 0.076 & $0.053 \pm 0.000$ & $(\mathrm{TGA})_{\mathrm{n}}(\mathrm{TA})_{\mathrm{n}}$ & 73 & 13 & $208-244$ & 55 \\
& & & & & $(\mathrm{CA})_{\mathrm{n}}$ & & & & \\
$\mathrm{A} 3$ & 0.74 & 0.96 & 0.223 & $0.000 \pm 0.000$ & $(\mathrm{GT})_{\mathrm{n}}(\mathrm{GA})_{\mathrm{n}}$ & 69 & 37 & $287-412$ & 55 \\
$\mathrm{~B} 8$ & 0.81 & 0.96 & 0.158 & $0.000 \pm 0.000$ & $(\mathrm{GA})_{\mathrm{n}}$ & 69 & 40 & $176-332$ & 50 \\
\hline
\end{tabular}

${ }^{a}$ Observed heterozygosity (all individuals with one ambiguous allele were treated as homozygotes when testing for deviations from Hardy-Weinberg).

${ }^{b}$ Expected heterozygosity (unbiased estimate [Nei, 1978]).

${ }^{c}$ Calculated using Genepop v3.3, according to Weir and Cockerham (1984).

${ }^{d} P$ value associated with a test for heterozygote deficiency, as predicted by Hardy-Weinberg equilibrium.

eSample size.

${ }^{f}$ Unique paternal alleles sampled indirectly through offspring are included in the size range but not in $n$ values or number of alleles for a given locus.

\section{RESULTS}

\section{Population Characterization}

Five highly polymorphic microsatellite loci were identified and characterized (Table II). Two of these loci (A3 and B8) were significantly deficient in heterozygotes as expected from Hardy-Weinberg predictions $(P \pm \mathrm{SE}=$ $0.000 \pm 0.000, P \pm \mathrm{SE}=0.000 \pm 0.000$ ). However, we suspect that these two loci provide unreliable results due to the presence of null alleles (see Discussion). None of the other three loci deviated significantly from expectations, although locus A11 did exhibit some deficiency of heterozygotes. Global tests for heterozygote deficiency using all five loci were significantly deficient in heterozygotes $(P \pm \mathrm{SE}=0.0027 \pm 0.0027)$, but tests using only loci A6, A7, and A11 showed no significant deficiency of heterozygotes $(P \pm \mathrm{SE}=0.328 \pm 0.035)$. The population-wide sample of genotypes did not exhibit a significantly higher variance for the number of homozygous loci per individual than expected by chance $(P=0.629)$.

\section{Progeny Array Data}

Based on a visual inspection of offspring genotypes and subtraction of the maternal contribution, the genotypes of all offspring at every locus 
could best be explained by a single male sire per clutch. No more than two paternally contributed alleles were seen at any of the three loci within a family. The most likely parameter values from LAMP were $m=1, k=$ 0.999 , and $\mu=0$. Even though the most likely proportion of multiply mated clutches $(m)$ was 1 (all clutches multiply mated), the reproductive skew was found to be $99.9 \%$. A skew of $k \sim 1$ indicates that any multiply mated females produce clutches that are fathered by only a single sire (i.e., one male sires $\sim 100 \%$ of the offspring within a clutch). Biologically, this has the same significance as $m=0$ (no multiple mating). Situations where $m=0$ and/or $k=1$ were all found to be much more likely than other parameter values (Fig. 2). The combined paternity exclusion probability across all three loci used for paternity analysis (A6, A7, and A11) was 0.987 . This means that if two males had contributed to any set of the sampled offspring within a clutch, there is a probability of 0.987 that both males would have been detected. The average relatedness within a clutch was found to be $r(95 \% \mathrm{CI})=0.4827$ $( \pm 0.0398)$. The expected average $r$, given a single sire per clutch, would be $r=0.5$. No paternal genotypes were shared among the 26 clutches sampled.

Pairwise relatedness estimates within mating pairs were variable (Table III), but the average relatedness between mothers and fathers of a given clutch was not found to differ significantly from $0(t=-0.6393$, $\left.P=0.5285, r_{\text {avg }}[95 \% \mathrm{CI}]=-0.022[ \pm 0.072]\right)$. Relatedness values less than 0 indicate fewer shared alleles than expected under random mating. The same qualitative result was also given by a nonparametric (Wilcoxon

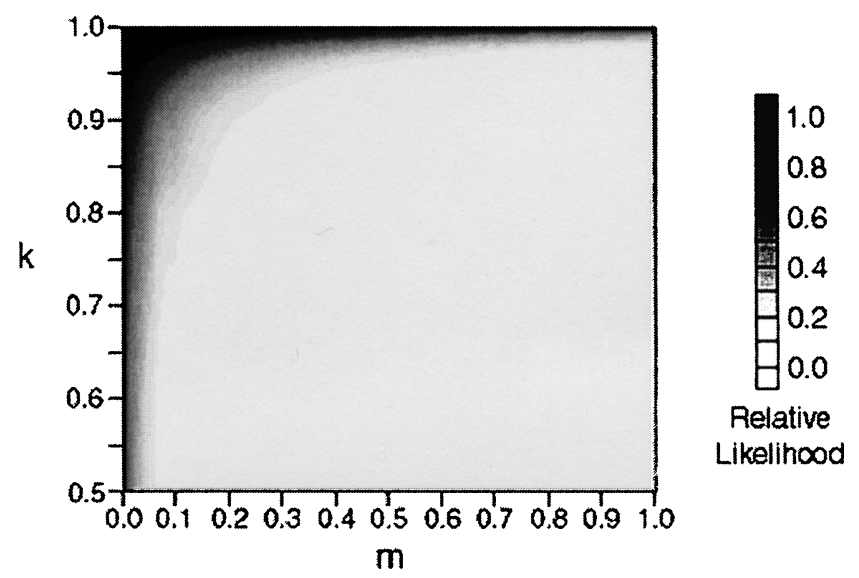

Fig. 2. Relative likelihoods for all possible values of reproductive skew $(k)$ and proportion of clutches multiply mated $(m)$. Darker areas indicate a greater likelihood. 
sign-rank) test ( $W=-48.000, d f=25, P=0.230)$. The data did not differ significantly from a normal distribution, but given the small sample size, the confidence interval should be noted with caution.

\section{DISCUSSION}

\section{Paternity Analysis}

All highly likely parameter values (relative likelihood, $>0.974$ ) had the same biological interpretation: single paternity within a clutch (Fig. 2). Determination of paternity through the subtraction of maternal alleles from progeny genotypes gave an identical result, with no more than two paternal alleles ever having been observed at any of the three loci in all 26 clutches. No instances of polygyny were observed among the paternal genotypes inferred from the progeny array data. However, given the small number of clutches sampled, it is highly unlikely that more than one clutch sired by a single male, even if polygyny occurs, would have been sampled.

Inbreeding does not seem to be a feature of the mating system, as there was no increase in the variance of multilocus homozygosity within individuals as determined by population-level sampling $(P=0.629)$, the average relatedness between dams and sires as determined through progeny array data was $\sim 0\left(r_{\mathrm{avg}}[95 \% \mathrm{CI}]=-0.022 \pm 0.072\right)$, and the average relatedness among clutchmates was not greater than $0.5(r[95 \% \mathrm{CI}]=0.4827[ \pm 0.0398])$.

Given the possible benefits of using sperm from multiple males and the observation (under laboratory conditions) of pursuit of a single female by multiple males, it is surprising to find that no cases of multiple paternity within a clutch were observed. Producing clutches that are genetically variable may be advantageous to a mother as a bet-hedging tactic in the face of a variable physical or biological environment (Jennions and Petrie, 2000). Additionally, mating with multiple males may prove advantageous if a single mating does not provide a female with enough sperm to fertilize all of her eggs (Godfray, 1994).

Few data exist on the interactions between adult burrower bugs in the field, so it is unknown exactly how mating occurs or who "controls" the mating process. If mating is male-controlled, males may deter other males from mating with an already mated female by guarding her, such as occurs in the soapberry bug Jadera haematoloma (Carroll, 1991). Another possibility is the existence of a high level of sperm competition between males, leading to the complete exclusion of sperm from all other mates aside from the successful male. Such strong sperm competition may be to the advantage of females, such that their sons will be the offspring of the male with the 
most successful sperm (Jennions and Petrie, 2000). Sperm precedence due to the order of mating could also generate the observed pattern, as seen in the water bug Abedus herberti (Smith, 1979).

If the siring of a clutch is controlled by females, our results suggest that there is either a physiological constraint on females prohibiting the use of sperm from more than one male (such as the limited capacity of a sperm storage organ) or some selective pressure toward singly sired clutches (controlled either behaviorally by refusing further mates or through the cryptic mate choice of particular sperm [Brian, 1983; Snyder, 1924]). Ecological constraints, such as spatial or temporal distribution of potential mates, could also limit the possibility of mating multiply.

One possible benefit of single paternity within a clutch to a female is the pattern of within-clutch relatedness that is generated among her offspring. This pattern may have implications for the resolution of the parent-offspring conflict over parentally provisioned resources. All else being equal, a mother would expect higher fitness if conflict among her offspring for limited provisioned resources was reduced (Godfray and Parker, 1992). Such a reduction of conflict would be more likely to occur in a clutch where all offspring share a single sire versus clutches with multiple sires and, therefore, lower relatedness. Consistent with this prediction, a comparative study of birds suggests that the overall level of offspring begging is reduced when withinclutch relatedness is increased (Briskie et al., 1994). In mixed broods, it may be possible for imprinting of paternal competitive behavior genes (which are unconstrained by the survival of the mother) to increase offspring begging beyond the maternal optimum (Haig, 1997). The ability to manipulate the number of sires per clutch, then, may be used as a "tool" by mothers to reduce levels of offspring begging for increased maternal provisioning. An interesting comparison could be made with a congener burrower bug, $S$. bicolor. This species does not actively provision offspring but, rather, leads them to host plants to feed on their own (Southwood and Leston, 1959). In such a case, the food source should not be as limiting, thereby decreasing the selective pressure for a single sire.

\section{Inbreeding and the Confounding Effect of Null Alleles}

Two microsatellite loci (A3 and B8) exhibited a significant deficiency in heterozygotes, while the other three loci did not. Other genetic patterns that are expected to be generated by inbreeding were not seen. Considering all the data together, we conclude that inbreeding does not occur in this population. First, inbreeding should produce a deficiency in heterozygotes at all loci, unlike the highly variable pattern observed over these five loci 
Table III. Pairwise Relatedness Between Parents from Each Family

\begin{tabular}{lcc}
\hline Family & Relatedness between parents & Number of loci \\
\hline 1 & -0.217 & 3 \\
2 & 0.068 & 3 \\
3 & 0.077 & 3 \\
4 & 0.113 & 2 \\
5 & -0.204 & 3 \\
6 & -0.059 & 3 \\
7 & -0.225 & 2 \\
8 & 0.224 & 3 \\
9 & -0.242 & 2 \\
10 & -0.078 & 2 \\
11 & -0.095 & 3 \\
12 & 0.049 & 3 \\
13 & -0.158 & 2 \\
14 & -0.049 & 3 \\
15 & -0.007 & 2 \\
16 & -0.196 & 1 \\
17 & -0.139 & 2 \\
18 & -0.015 & 3 \\
19 & 0.564 & 2 \\
20 & -0.084 & 3 \\
21 & 0.245 & 3 \\
22 & 0.087 & 3 \\
23 & 0.039 & 3 \\
24 & -0.081 & 2 \\
25 & -0.192 & 3 \\
26 & -0.009 & 2 \\
Mean relatedness $(95 \% \mathrm{CI})$ & $-0.022( \pm 0.072)$ & \\
\hline
\end{tabular}

( $F_{\mathrm{IS}}$ values, -0.058 to 0.223 ; Table II). Second, the calculations of pairwise relatedness between mothers and putative fathers yielded only 4 of 26 pairs with $r>0.1$ (Table III) and the average relatedness was not significantly different from zero $(P=0.5285)$. Additionally, the average relatedness among offspring within a clutch was not greater than $0.5(r[95 \% \mathrm{CI}]=0.4827$ $[ \pm 0.0398])$. Finally, the expected pattern of increased variance for number of homozygous loci in a population with a variable history of inbreeding was not observed $(P=0.629)$, even when A3 and B8 were excluded from the analysis. Instead, it seems likely that these two loci (A3 and B8) suffer from the confounding effects of null alleles (Pemberton et al., 1995).

Other qualitative differences existed between those loci with putative null alleles (A3 and B8) and the three others. Amplified products from these two loci produced a large number of stutterbands, were much more polymorphic with many alleles observed only once, and produced very closely spaced alleles (sometimes only $1 \mathrm{bp}$ apart), possibly indicative of a higher mutation rate. Additionally, a larger number of individuals gave no noticeable product 
from genotyping reactions for these two loci, possibly due to the presence of null allele homozygotes. For these reasons, we believe that there is not frequent mating between closely related individuals in this population and that loci A3 and B8 should be disregarded because of the high potential for the existence of null alleles (Pemberton et al., 1995).

\section{CONCLUSION}

Using molecular markers, we find no evidence for multiple sires within a clutch or for inbreeding in this population of burrower bugs. This result is surprising considering the number of insect species that mate multiply. We hypothesize that single-paternity clutches may be important in this system to increase the relatedness of offspring and thereby reduce the potential for sibling rivalry. Further experiments comparing mating systems within and among species, and their effect on sibling rivalry, would allow this hypothesis to be tested.

\section{ACKNOWLEDGMENTS}

Special thanks go to B. J. Ridenhour for assistance with data analysis and technical issues. Thanks are due to M. J. Wade, L. Rieseberg, and L. Delph for use of equipment and facilities and to M. Arntz, J. Durphy, S. J. B. Cooper, and M. Welch for technical assistance. Helpful comments were given by two anonymous reviewers and members of the Brodie Lab. This work was supported by a fellowship from the Arnold and Mabel Beckman Foundation to J.M.B., research funds from the Center for the Integrative Study of Animal Behavior (IU) to A.F.A., and NSF Grant IBN-0130880 to E.D.B. III.

\section{REFERENCES}

Agrawal, A. F., Brodie, E. D., III, and Brown, J. (2001). Parent-offspring coadaptation and the dual genetic control of maternal care. Science 292: 1710-1712.

Andersson, M. B. (1994). Sexual Selection, Princeton University Press, Princeton, NJ.

Arnqvist, G., and Nilsson, T. (2000). The evolution of polyandry: Multiple mating and female fitness in insects. Anim. Behav. 60: 145-164.

Bennet, J. H., and Binet, F. E. (1956). Association between Mendelian factors with mixed selfing and random mating. Heredity 10: 51-56.

Birkhead, T. R., and Møller, A. P. (1992). Sperm Competition in Birds: Evolutionary Causes and Consequences, Academic Press, London.

Brian, M. V. (1983). Social Insects: Ecology and Behavioral Biology, Chapman and Hall, London.

Briskie, J. V., Naugler, C. T., and Leech, S. M. (1994). Begging intensity of nestling birds varies with sibling relatedness. Proc. Roy. Soc. Lond. B 258: 73-78. 
Brown, A. H. D., Feldman, M. W., and Nevo, E. (1980). Multilocus structure of natural populations of Hordeum spontaneum. Genetics 96: 523-536.

Carroll, S. P. (1991). The adaptive significance of mate guarding in the soapberry bug, Jadera haematoloma (Hemiptera: Rhopalidae). J. Insect Behav. 4: 509-530.

Castric, V., Bernatchez, L., Belkhir, K., and Bonhomme, F. (2002). Heterozygote deficiencies in small lacustrine populations of brook charr Salvelinus fontinalis Mitchill (Pisces, Salmonidae): A test of alternative hypotheses. Heredity 89: 27-35.

Dodds, K. G., Tate, M. L., McEwan, J. C., and Crawford, A. M. (1996). Exclusion probabilities for pedigree testing farm animals. Theor. Appl. Genet. 92: 966-975.

Dupuis, C. (1970). Heteroptera. In Tuxen, S. L. (ed.), Taxonomist's Glossary of Genitalia in Insects, Munksgaard, Copenhagen, pp. 190-209.

Estoup, A., Scholl, A., Pouvreau, A., and Solignac, M. (1995). Monoandry and polyandry in bumblebees (Hymenoptera; Bombinae) as evidenced by highly variable microsatellites. Mol. Ecol. 4: 89-93.

Godfray, H. C. J. (1994). Parasitoidis: Behavioral and Evolutionary Ecology, Princeton University Press, Princeton, NJ.

Godfray, H. C. J., and Parker, G. A. (1992). Sibling competition, parent-offspring conflict and clutch size. Anim. Behav. 43: 473-490.

Guo, S. W., and Thompson, E. A. (1992). Performing the exact test of Hardy-Weinberg proportions for multiple alleles. Biometrics 48: 361-372.

Haig, D. (1997). Parental antagonism, relatedness asymmetries, and genomic imprinting. Proc. Roy. Soc. Lond. B 264: 1657-1662.

Haldane, J. B. S. (1949). The association of characters as a result of inbreeding and linkage. Ann. Eugen. 15: 15-23.

Hamilton, W. D. (1964). The genetical evolution of social behaviour, I \& II. J. Theo. Biol. 7: $1-52$.

Hartl, D. L., and Clark, A. G. (1997). Principles of Population Genetics, 3rd ed., Sinauer Associates, Sunderland, MA.

Houston, A. I., and McNamara, J. M. (2002). A self-consistent approach to paternity and parental effort. Philos. Trans. Roy. Soc. Lond. Ser. B 357: 351-362.

Jennions, M. D., and Petrie, M. (2000). Why do females mate multiply? A review of the genetic benefits. Biol. Rev. 75: 21-64.

Jones, A. G. (2001). GERUD1.0: A computer program for the reconstruction of parental genotypes from progeny arrays using multilocus DNA data. Mol. Ecol. Notes 1 (available at http://dx.doi.org/10.1046/j.1471-8278.2001.00062.x).

Kichler, K., Holder, M. T., Davis, S. K., Márquez, R., and Owens, D. W. (1999). Detection of multiple paternity in the Kemp's ridley sea turtle with limited sampling. Mol. Ecol. 8: 819-830.

Kight, S. L. (1995). Do maternal burrower bugs, Sehirus cinctus Palisot (Heteroptera: Cydnidae), use spatial and chemical cues for egg discrimination? Can. J. Zool. 73: 815817.

Kight, S. L., and Cseke, J. J. (1998). The effects of ambient temperature on the duration of maternal care in a burrower bug (Heteroptera: Cydnidae). J. Kans. Entomol. Soc. 71: 183-187.

Koelewijn, H. P. (1998). Effects of different levels of inbreeding on progeny fitness in Plantago coronopus. Evolution 52: 692-702.

Lynch, M., and Ritland, K. (1999). Estimation of pairwise relatedness with molecular markers. Genetics 152: 1753-1766.

Margulis, S. W. (1997). Inbreeding-based bias in parental responsiveness to litters of oldfield mice. Behav. Ecol. Sociobiol. 41: 177-184.

Mock, D. W., and Parker, G. A. (1997). The Evolution of Sibling Rivalry, Oxford University Press, New York.

Moritz, R. F. A., Kryger, P., Koeniger, G., Koeniger, N., Estoup, A., and Tingek, S. (1995). High degree of polyandry in Apis dorsata queens detected by DNA microsatellite variability. Behav. Ecol. Sociobiol. 37: 357-363. 
Mutikainen, P., and Delph, L. F. (1998). Inbreeding depression in gynodioecious Lobelia siphilitica: Among-family differences override between-morph differences. Evolution 52: 1572 1582.

Nalepa, C. A., and Jones, S. C. (1991). Evolution of monogamy in termites. Biol. Rev. 66: 83-97.

Pemberton, J. M., Slate, J., Bancroft, D. R., and Barnett, J. A. (1995). Nonamplifying alleles at microsatellite loci: A caution for parentage and population studies. Mol. Ecol. 4: 249-252.

Queller, D. C., and Goodnight, K. F. (1989). Estimating relatedness using genetic markers. Evolution 43: 258-275.

Raymond, M., and Rousset, F. (1995). GENEPOP Version 1.2, population-genetics software for exact tests and ecumenicism. J. Hered. 86: 248-249.

Rozen, S., and Skaletsky, H. J. (2000). Primer3. On the web for general users and for biologist programmers. In: Kravetz, S., and Misener, S. (eds.), Bioinformatics Methods and Protocols: Methods in Molecular Biology. Humana Press, Totowa, NJ, pp. 365-386. Code available at http://www-genome.wi.mit.edu/genome_software/other/primer3.html

Sheldon, B. C. (2002). Relating paternity to paternal care. Philos. Trans. Roy. Soc. Lond. Ser. B 357: $341-350$.

Sites, R. W., and McPherson, J. E. (1982). Life history and laboratory rearing of Sehirus cinctus cinctus (Hemiptera: Cydnidae), with descriptions of immature stages. Ann. Entomol. Soc. Am. 75: 210-215.

Smith, R. L. (1979). Repeated copulation and sperm precedence: Paternity assurance for a male brooding water bug. Science 205: 1029-1031.

Snyder, T. E. (1924). 'Adaptations' to social life: The termites (Isoptera). Smithson. Misc. Collect. 76: $1-14$.

Southwood, T. R. E., and Leston, D. (1959). Land and Water Bugs of the British Isles, Frederick Warne, London.

Wade, M. J. (1996). Adaptation in subdivided populations: Kin selection and interdemic selection. In Rose, M. R., and Lauder, G. (eds.), Evolutionary Biology and Adaptation, Sinauer Associates, Sunderland, MA, pp. 381-405.

Weir, B. S., and Cockerham, C. C. (1984). Estimating F-statistics for the analysis of population structure. Evolution 38: 1358-1370. 